\title{
The Review of Construction Technologies Using Fuzzy-Ball Workover Fluid in Well C22 and Well F20 of SZ36-1 Offshore Oilfield
}

\author{
Shan WANG ${ }^{1}$, Yao LIU ${ }^{2, *}$, Jian-Hua BAI ${ }^{3}$, Xin MENG ${ }^{2}$, Jian SONG ${ }^{2}$ \\ ${ }^{1}$ China National Offshore Oil Corporation (CNOOC) Research Institute, China \\ ${ }^{2}$ China University of Petroleum, China \\ ${ }^{3}$ Bohai Research Institute of Petroleum/CNOOC Ltd. Tianjin Branch, China \\ 250088096@qq.com \\ ${ }^{*}$ Corresponding author
}

Keywords: Workover Fluid, Fuzzy-Ball, Construction Technology.

\begin{abstract}
SZ36-1 oil field is an offshore oilfield with serious lost circulation as well as formation damage. To avoid lost circulation and formation damage during workover in offshore oil fields, a novel multi-functional Fuzzy-Ball Workover Fluid (FBWF) was developed and used in well C22 and well F20 of SZ36-1 oil field. In this article, we review the construction technologies using FBWF in two wells, which include preparation, injecting, flowing back. By contrasting the construction technologies in two wells, we conclude some experiences in construction technologies for offshore oilfield workover using FBWF. These achievements can also help the followers while using FBWF in offshore oilfield workover.
\end{abstract}

\section{Introduction}

Guided by Fuzzy Plugging Theory ${ }^{1}$ (L.H. Zheng, et al, 2012), Lihui Zheng developed Fuzzy-Ball working fluid to solve the lost circulation problems ${ }^{2}$ (L.H. Zheng, et al, 2010). The Fuzzy-Ball drilling fluid was firstly used for drilling ${ }^{3}$ and its plugging and controlling lost circulation ability has been well proved (D.G. Wang, et al, 2011). Then the Fuzzy-Ball drilling fluid was used for workover ${ }^{4}$ (Y.G. Zhao, et al, 2012) and well completion ${ }^{5}$ (Z.C. Li, 2013). Also, the Fuzzy-Ball working Fluid was used in coalbed methane drilling ${ }^{6}$ (F.P. Sun, et al, 2012). The Fuzzy-Ball working Fluid had also been used in some special cases, such as horizontal wells ${ }^{7}$ (S.Z. Meng, et al, 2012), drilling highly deviated wells ${ }^{8}$ (L.X. Kuang, et al, 2012) and large borehole wells ${ }^{9}$ (J.R. Sun, 2014).

The FBWF has been widely used in wells with the lost circulation ${ }^{10}$ (L.H. Zheng, et al, 2012). It has strong ability in controlling lost circulation and plugging. With the development of Fuzz-Ball technology and the constant improvement of its theory, a novel multi-functional Fuzzy-Ball Workover Fluid (FBWF) was developed and applied in Well C22 and Well F20 of SZ36-1 offshore oilfield. Both two wells have serious leakage problems and the leakage needs to be solved during workover operations.

In this article, we review the workover process using Fuzzy-Ball workover fluid in Well C22 and Well F20. Through the workover process, we concentrate on the construction technology, which include preparation, injecting, flowing back. Let's take a look at the detail of the construction technology of the two wells.

\section{The Design of Well C22 and Well F20}

1) The design amount of FBWF using in Well C22 and Well F20.

The formula of FBWF's volume is:

$$
Q=Q_{1}+Q_{2}=\pi\left(\left(r_{1}+r_{2}\right)^{2}-r_{1}^{2}\right) h \phi+Q_{2}
$$


Where $\mathrm{Q}$ is the total volume of FBWF, $\mathrm{Q}_{1}$ is the volume of working FBWF, $\mathrm{Q}_{2}$ is the volume of unusable FBWF, including residual liquid in the tank bottom and pipeline. $r_{1}$ is casing radius, $r_{2}$ is the temporary blocking formation depth, $\mathrm{h}$ is perforation thickness, $\varphi$ is porosity, $25-35 \%$.

2) The performance of FBWF using in Well C22 and Well F20.

The performance of FBWF using in Well C22 and Well F20 are shown in Table 1.

Tab. 1 The Performance of FBWF Using in Well C22 and Well F20

\begin{tabular}{|c|c|c|l|l|c|c|c|c|c|c|}
\hline Performance & $\theta_{600}$ & $\theta_{300}$ & $\theta_{6}$ & $\theta_{3}$ & $\begin{array}{c}\rho \\
\mathrm{g} / \mathrm{cm}^{3}\end{array}$ & $\begin{array}{c}\mathrm{AV} \\
\mathrm{mPa} \cdot \mathrm{s}\end{array}$ & $\begin{array}{c}\mathrm{PV} \\
\mathrm{mPa} \cdot \mathrm{s}\end{array}$ & $\begin{array}{c}\mathrm{YP} \\
\mathrm{Pa}\end{array}$ & $\begin{array}{c}\mathrm{YP} / \mathrm{PV} \\
\mathrm{Pa} / \mathrm{mPa} \cdot \mathrm{s}\end{array}$ & $\mathrm{pH}$ \\
\hline $\mathrm{C} 22$ & 68 & 48 & 8 & 6 & 0.94 & 34 & 20 & 14 & 0.7 & 10 \\
\hline F20 & 126 & 96 & 21 & 17 & 1.02 & 63 & 30 & 33 & 1.1 & 11 \\
\hline
\end{tabular}

According indoor research and the site applicant, the performance of C22 is more suitable for SZ36-1 oil field workover operation.

\section{The workover Review of Well C22}

SZ36-1 oil field is an offshore oil field which has been developed for over twenty years. Well C22 began to produce on August 26th, 2001. It is a conventional directional well with depth of $2128 \mathrm{~m}$ and perforation length of $157.5 \mathrm{~m}$. Its maximum deviation angle is $48.8^{\circ}$ and the porosity is $25-35 \%$.

On March $27^{\text {th }}, 2011,180 \mathrm{~m}^{3}$ water was injected at injection rate of $10 \mathrm{~m}^{3} / \mathrm{h}$ to test whether there was a loss or not. There was no liquid returned and the circulation could be established.

On March $28^{\text {th }}, 2011,49 \mathrm{~m}^{3}$ FBWF was prepared, with density of $0.94 \mathrm{~g} / \mathrm{cm}^{3}$, plastic viscosity of 20 $\mathrm{mPa} \cdot \mathrm{s}$, dynamic shear of $14 \mathrm{~Pa}$, and dynamic plastic ratio of 0.7 .

On March $28^{\text {th }}, 2011,42 \mathrm{~m}^{3}$ FBWF and $8 \mathrm{~m}^{3}$ formation water was injected through reverse circulation. There was pressure at the wellhead, and then formation water was slowly injected into the well to test the bearing capacity. The injection was stopped when the pressure increased to $8.1 \mathrm{MPa}$ and the wells was closed for one day.

On March $29^{\text {th }}, 2011$, the formation water was used to clean the well through reverse circulation and $30 \mathrm{~m}^{3}$ mixture of heavy oil and FBWF returned. The mixture was broken in the original mud tank, and then entered the production process.

On March $30^{\text {th }}, 2011$, the electric submersible pump started producing at $35 \mathrm{~Hz}$ after the workover ended. Then the day after, pump frequency was enhanced to $40 \mathrm{~Hz}$ and kept for 3 days. After that, the pump frequency was enhanced by $2 \mathrm{~Hz}$ each day to $50 \mathrm{~Hz}$, which was the pump's working frequency. Then Well C22 turn into normal production.

\section{The Workover Review of Well F20}

Well F20 began to produce on December 3th, 2000. It is a conventional directional well with depth of $1854 \mathrm{~m}$ and perforation length of $32.8 \mathrm{~m}$. Its maximum deviation angle is $42.8^{\circ}$ and the porosity is 25-35\%.

On October $11^{\text {th }}, 2011,50 \mathrm{~m}^{3}$ FBWF was prepared, with density of $1.02 \mathrm{~g} / \mathrm{cm}^{3}$, plastic viscosity of $30 \mathrm{mPa} \cdot \mathrm{s}$, dynamic shear of $33 \mathrm{~Pa}$, and dynamic plastic ratio of $1.1 .40 \mathrm{~m}^{3} \mathrm{FBWF}$ and $8 \mathrm{~m}^{3}$ formation water was injected through reverse circulation. There was pressure at the wellhead, and then formation water was slowly injected into the well to test the bearing capacity. The injection was stopped when the pressure increased to $14 \mathrm{MPa}$ and the wells was closed for two days.

On October $13^{\text {th }}, 2011$, the formation water was used to clean the well through reverse circulation and $18-19 \mathrm{~m}^{3}$ FBWF, $6-7 \mathrm{~m}^{3}$ mixture of heavy oil and sand returned.

On October $14^{\text {th }}, 2011$, the electric submersible pump started producing at $30 \mathrm{~Hz}, 5 \mathrm{~m}^{3}$ mixture of formation water and FBWF returned. The pump frequency then enhanced to $50 \mathrm{~Hz}$, there was no liquid returned and the pump was stopped. $3 \mathrm{~m}^{3}$ breaker was prepared. 
On October $15^{\text {th }}, 2011$, the breaker was injected through positive circulation. The pump still cannot be started.

On November $20^{\text {th }}, 2011$, diesel was injected and the pump was inspected.

On November $27^{\text {th }}, 2011$, the pump started producing at $35 \mathrm{~Hz}$ and kept for 2 days.

On November $29^{\text {th }}, 2011$, pump frequency was enhanced to $40 \mathrm{~Hz}$ and kept for 2 days.

On December 2th, 2011, pump frequency was enhanced to $50 \mathrm{~Hz}$, which was the pump's working frequency. Then Well F20 turn into normal production.

\section{The Construction Technologies Using FBWF}

Through the workover review of Well C22 and Well F20, we can summarize the construction technologies using FBWF like the followings:

\section{Preparation}

The preparation of fuzzy ball working fluid is simple and no additional equipment is needed.

1) The site preparation and injection time of FBWF is acceptable.

The preparation process is simple and the existing equipment can fully meet the requirements of injection. It took 3 hours to prepare $49 \mathrm{~m}^{3} \mathrm{FBWF}$ in Well C22. The injection process of FBWF is as same as that of formation water, and it does not have an impact on the pump and pipeline.

2) The site equipment will meet the requirement.

According to the C22 and F20 wells, the site use the mud pump to cycle and the preparation can be easily done after the drugs is injected into the mud pool. The preparation of fuzzy ball drilling fluid is simple and no additional equipment is required.

\section{Injection}

The slug type plugging and the reverse circulation are advised for injection.

1) The slug type plugging will meet the requirement of workover.

The slug type plugging is injecting FBWF into the well bottom and return to where is a little higher above the perforation formation. And then the formation water is injected into the well, the pressure at the well head is measured to judge whether the foramtion is plugged sucefucessfully or not. The applicant of C22 and F20 wells showed that the slug type plugging was enough for workover.

2) The reverse circulation is advised for workover.

The reverse circulation is that injecting the workover liquid through the annulus. And the liquid will return the wellhead inside the drill pipe. The area of the annulus is larger than the area of the drill pipe, so the liquid is easier to inject. What's more, during the reverse circulation, the FBWF can plug as soon as it contact with the leakage formation. The photo of the reserve circulation is shown in Figure 1.

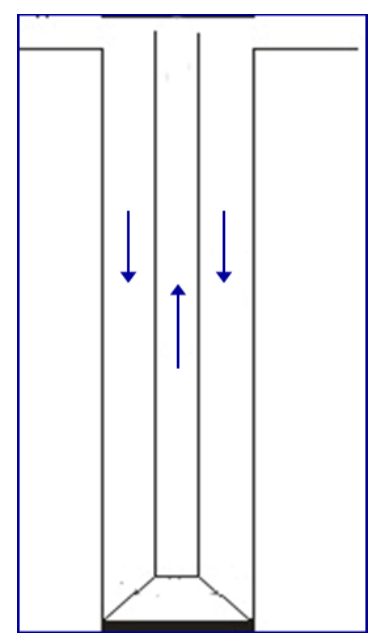

Fig. 1 The Photos of the Reserve Circulation 


\section{Flowing Back}

There is no need to break to produce after workover and the pump should be started at a low frequency.

1) There is no need to break to produce after workover.

According to the FBWF ability, there is no need to break to produce after workover. The pump can get started at a low frequency after the workover is done. The breaker would be injected when there are problems about flowing back and then the pump can get started to produce.

2) The rest FBWF and the mixture that downhole liquid flowed back broke and then entered the production process. There was no impact on the subsequent production.

When the workover was completed, the rest FBWF and the downhole liquid flowed back were mixed in the tank for breaking. 3\% breaker was added and the mixture was blended for 90 minutes. The apparent viscosity of the mixture before breaking was $34 \mathrm{mPa} \bullet \mathrm{s}$, and the apparent viscosity of the mixture after breaking in $90 \mathrm{~min}$ was $3.5 \mathrm{mPa} \cdot \mathrm{s}$. The apparent viscosity measured by six speed rotating viscometer can meet the requirements of entering the production process.
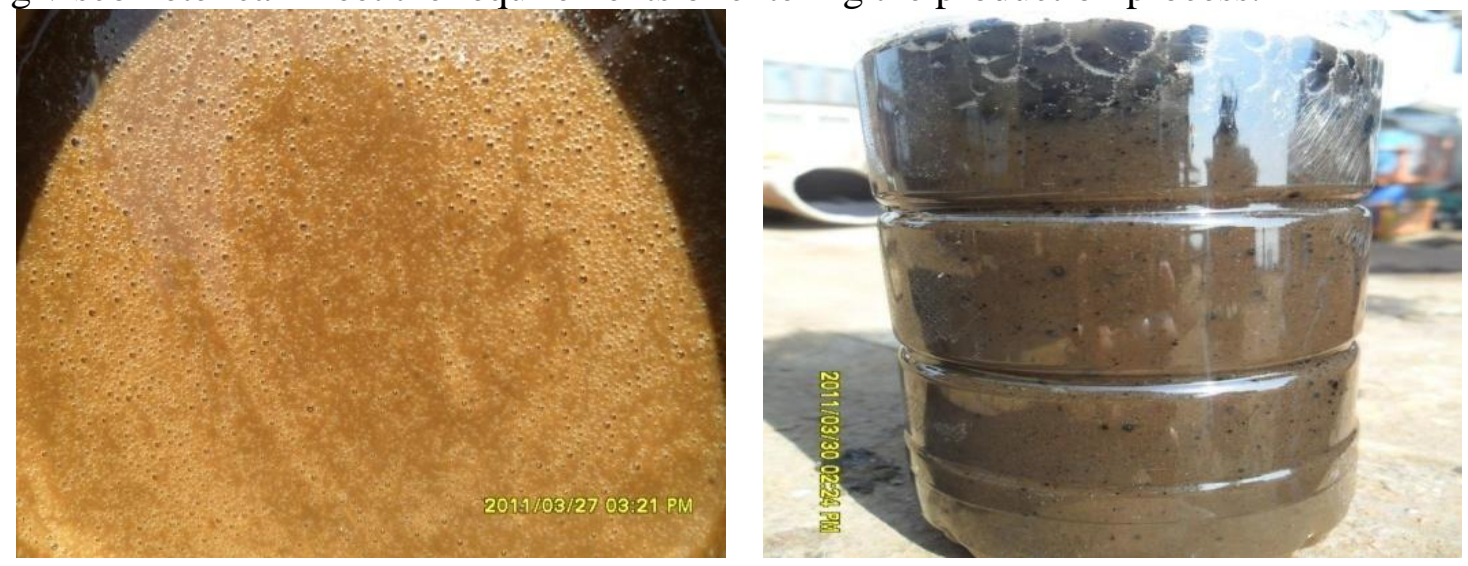

Fig. 2 The Photos of FBWF before Breaking in the Stirring Cup (left) and the Photos of FBWF after Breaking in the Plastic Bottles (right)

3) Starting the pump at a low frequency

The normal situation: the pump can start at a low frequency after the workover.

Through the preliminary study, the pump starting frequency after workover using FBWF should not exceed $35 \mathrm{~Hz}$. If the conditions allow, the lower pump starting frequency is also sure. After starting producing, if the liquid returned contain oil, the pump frequency should maintain the starting frequency for a few days and then arouse the frequency gradually. The advice prompting frequency velocity is $2 \mathrm{~Hz} / \mathrm{d}$ and the maximum velocity $5 \mathrm{~Hz} / \mathrm{d}$ should not be exceeded.

The abnormal situation: the breaker should be injected.

After the breaker injected, the pump starting frequency for producing should not more than $35 \mathrm{~Hz}$. If the conditions allow, the lower pump starting frequency is also sure. After starting producing, if the liquid returned contain oil, the pump frequency should maintain the starting frequency for a few days and then arouse the frequency gradually. The advice prompting frequency velocity is $2 \mathrm{~Hz} / \mathrm{d}$ and the maximum velocity $5 \mathrm{~Hz} / \mathrm{d}$ should not be exceeded.

\section{Summary}

FBWF can be successfully used for workover. It can not only plug the formation but also enhance oil production. What's more, FBWF has no adverse effect on the construction technology during workover operation.

In construction technology, the first thing is preparation. The preparation of fuzzy ball working fluid is simple and no additional equipment is needed. What's more, the site preparation and injection time of FBWF are acceptable. 
Secondly, the injection is also important. Through the applicant of well C22 and well F20, the slug type plugging and the reverse circulation are advised for workover using FBWF.

Finally, it comes to flowing back. There is no need to break to produce after workover. The rest FBWF and the mixture that downhole liquid flowed back broke and then entered the production process. There was no impact on the subsequent production.

The most special construction technology of using FBWF is the pump starting frequency. The pump starting frequency after workover using FBWF should not exceed $35 \mathrm{~Hz}$. After starting producing, if the liquid returned contain oil, the pump frequency should maintain the starting frequency for a few days and then arouse the frequency gradually. The advice prompting frequency velocity is $2 \mathrm{~Hz} / \mathrm{d}$ and the maximum velocity $5 \mathrm{~Hz} / \mathrm{d}$ should not be exceeded.

The construction technologies of well C22 and well F20 give some instructions about preparation, injection and flowing back during the workover using FBWF. We can conclude that these construction technologies can also be spread to other oil fields' workover using FBWF.

\section{Conflicts of interest}

This paper has no conflict of interest.

\section{Acknowledgements}

Supported by the national major project of the mechanism and performance evaluation of Fuzzy-Ball working Fluid on heavy oil pressure failure field (No.2011ZX05024-002). Thanks for CNOOC Ltd. Tianjin Branch's field test support. Thanks for LihuiLab for providing indoor research data.

\section{References}

[1]L.H. Zheng, M.W. Zhang. Review of basic theory for lost circulation control [J]. Oil Drilling \& Production Technology, 2012.9, 32(5): 1-9.

[2]L.H. Zheng, L.S. Kong, Y. Cao, et al. The mechanism for fuzzy-ball working fluids for controlling \& killing lost circulation[J].Chinese Science Bulletin, 2010, 55(15): 1520-1528.

[3]D.G. Wang, Y.Y. He, Y. Bu, et al. Practice of fuzzy-ball drilling fluid technology in Well Ji X coal bed methane[J]. Oil Drilling \& Production Technology, 2011, 33(5): 93-95.

[4]Y.G. Zhao, X.G. Qiang, J. Cui, et al. Self-matching Fuzzy Ball Workover Fluid Temporary-sealing Sand Washing Technology for Horizontal Well in Jidong Oilfield[J]. Drilling Fluid \& Completion Fluid, 2012.9, 29(5): 89-91.

[5]Z.C. Li. Practice of Fuzzy Ball Cementing Pad Fluid in Leakage Zone of Naiman Well NXY[J]. Advanced Materials Research, 2013, 773: 714-719.

[6]F.P. Sun, J. Zhang, J. Li, et al. Fuzzy-Ball Drilling Fluid Technology for 215.9mm CBM Well and Horizontal Well[J]. China Coalbed Methane, 2012.4, 9(2): 18-21.

[7]S.Z. Meng, Z.B. Dou, B. Liu, et al. Fuzzy Ball Drilling Fluid Technology in CBM of Multilateral Horizontal Well FL-H2-L with Five Branch Holes[J]. Drilling Fluid \& Completion Fluid, 2012.1, 29(1): 5-8.

[8]L.X. Kuang, X. Zheng, M.J. Yuan, et al. Application of Fuzzy-ball Drilling Fluids to Coalbed Methane Development in Yanping 1\# Horizontal Well[J]. Nature Gas And Oil, 2012, 30(4): 39-42.

[9]J.R. Sun. Advanced Materials Reasearch-Study on controlling lost circulation of pilot hole in raise boring by using[J]. Advanced Materials Research, 2014, 988: 274-280.

[10]L.H. Zheng, Z.H. Zhang, M.W. Zhang. A novel lost circulation material: fuzzy ball working fluid[J]. Advanced Materials Research, 2012, 562-564: 145-151. 